\title{
DESIGN AND DEVELOPMENT OF A STEERING WHEEL FOR AN ENERGY EFFICIENT VEHICLE
}

\author{
Simeon Iliev, Dancho Gunev \& Emil Mitev
}
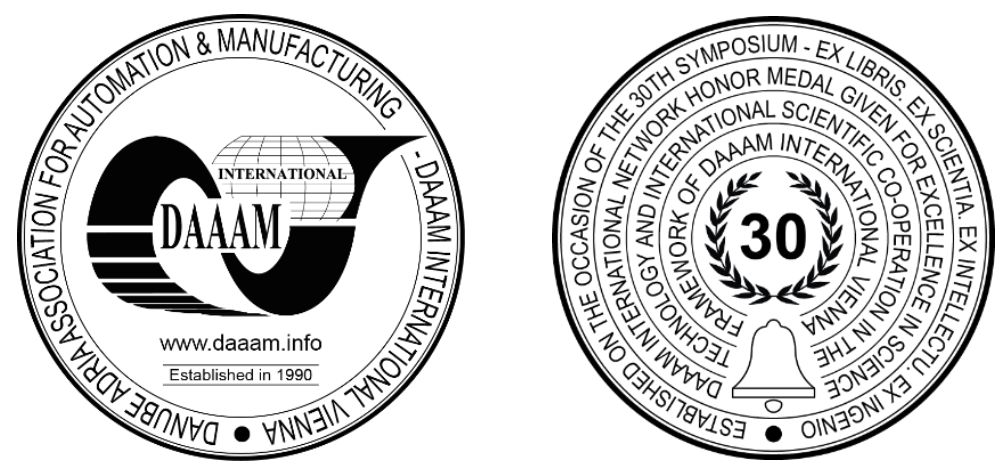

This Publication has to be referred as: Iliev, S[imeon]; Gunev, D[ancho] \& Mitev, E[mil] (2019). Design and Development of a Steering Wheel for an Energy Efficient Vehicle, Proceedings of the 30th DAAAM International Symposium, pp.0405-0414, B. Katalinic (Ed.), Published by DAAAM International, ISBN 978-3-902734-22-8, ISSN 1726-9679, Vienna, Austria

DOI: $10.2507 / 30$ th.daaam.proceedings.055

\begin{abstract}
The Shell Eco-Marathon (SEM) is an annual competition for engineering students, sponsored by Shell, in which participants design and fabricate special single seater racing vehicle to achieve the highest possible energy efficiency. In battery-electric class the teams have to cope with rules and restrictions, which concern specifications of the car such chassis, electric motor, controller and safety. This paper reports the analysis of a multifunctional steering wheel with a controller inside for driving an electric prototype vehicle in order to achieve minimum energy consumption during the completion of a race within a specified time. The objective is to reduce physical and psychic fatigue, reduce driving errors in terms of following the scenario (driving pattern) of an attempt and precision in using controls, in a way leading to minimum use of energy and improving quality of pilot's driving for the Shell Eco-marathon Europe 2018 race.
\end{abstract}

Keywords: Steering wheel; Arduino; Wheel speed sensor; Microcontroller

\section{Introduction}

Worldwide, in recent years, it has been observed intensive research to find out alternatives to fossil fuels because world's fossil fuel reserves are limited. Renewable energy represents a vast palette of natural energy resources, encompassing usable energy from the sun, wind, biomass (plant materials and animal waste), water and the earth itself (geothermal energy) [1], [2]. These are fundamentally different from conventional fuel sources in that they are renewed by nature over short time cycles and hence are not depletable, as are fossil fuels [3]. Energy efficiency can help meet our energy needs by reducing our demand for energy. Better energy management systems, advanced auto technology and energy-saving lighting and appliances have proven that economic growth can be achieved with lower energy consumption. One of the solutions that can be implemented in automotive transport is to optimize the engine efficiency and the maximized usage of energy. Vehicle efficiency can be optimized through advanced new technology, advanced materials and aerodynamics features such as streamlined design. Shell Eco-marathon (SEM) is an annual university and college competition sponsored by Shell that has the goal to compete with a more efficient vehicle for a given distance. This event challenges universities and colleges from all over the world to design and fabricate the most energy efficient vehicle. SEM races are not to be the fastest but to minimize the energy consumption of the vehicles. The winner is the most energy efficient vehicle. To minimize the equivalent consumption for the Shell Eco-marathon competition [4], 
expressed by the kilometres per kilowatt hour $(\mathrm{km} / \mathrm{kWh})$, (measured by Shell by the joulemeter.), the most important key factors are: weight, aerodynamic resistance, friction of the wheels and of the bearings, and at last but not least powertrain efficiency [5]. The proper motor control is a very important factor for minimal energy consumption. The electric motor must work in the zone with the maximum efficiency to avoid overheating the motor. Thanks to the possibility of the steering wheel, many of the powertrain parameters can be tracked and thus optimized for energy consumption. Good ergonomics on the steering wheel makes it easier for the pilot to work. This work shows the capabilities of a steering wheel used in the energy efficient vehicle.

\section{Five principles for ergonomic efficiency}

Shell Eco-marathon is a competition about energy efficiency. "Students are challenged to design, build and test energy-efficient cars, pushing the boundaries of what is technically possible. Students take their designs to the track in the Mileage Challenge to see which vehicle can compete to go the farthest on the least amount of fuel [6]." In many cases designers and engineers focusing their attention on vehicle itself, like an efficient technical system and after that trying to integrate somehow pilot there. As soon as there is a person who operates the vehicle, energy consumption will depend on his or her properties and precision in a process of driving. In other words, there is another meta-system which efficiency is crucial for a final amount of energy consumption. Efficiency of such human-machine systems is a subject of ergonomics. "Ergonomics is the study of the interaction between people and machines and the factors that affect the interaction. Its purpose is to improve the performance of systems by improving human machine interaction" [7].

Taking into account that fact - pilot is a main control part of human-vehicle system, one can say that design of that system must start from the driver, from defining best possible, comfortable working environment to achieve least amount of errors and misuse of controls. Constraints in this process are Shell Eco-marathon Official Rules [4] and engineering concept of the vehicle.

Main aspects of pilot comfort are concerned with: driving position, reach envelopes, field of sight, driver-control and display interaction, workload, cockpit microclimate.

Because of the extreme character of the project there are no common solutions for most of the problems. Driving position is very specific (close to horizontal), controls and displays are different (there are two brake pedals/levers). In these conditions standards providing guidance for seating accommodation (SAE J1517 and J4004), driver reach curves (SAE J287), and driver head clearance contour (SAE J1052) could be taken only as reference and there is a need of guiding ergonomic principles:

- Principle of using neutral posture/position [8]. A neutral posture is achieved when the muscles are at their resting length and the joint is naturally aligned [9].

- Principle of minimal moving of human body parts to fulfil goals of operation.

- Principle of minimal muscle force needed to fulfil goals of operation.

- Principle of avoiding action overlap in a process of controls use. Avoiding need to activate two or more controls simultaneously with one part of the human body.

- Principle of organizing controls in zones by functional similarities.

Base control in a vehicle is steering device (in usual situation-steering wheel).

Main controls of the vehicle are: start/stop, steering, accelerator / "dead man's safety device", brake-front, brake-rear, emergency shutdown actuator, horn, calibration, additional/spare. Secondary and tertiary controls are not presented.

Displays and indicators - there is only one complex display and one LED-indicator in the vehicle. Sound and vibrational indicators are not presented.

Steering device area is most important interaction point in the human-vehicle ergonomic system and by its quality of design and workmanship it contributes to efficiency of the system.

\subsection{Controls and displays/indicators outside steering device's area}

Brakes - using the 5th principle and because of two brake controls - one for the front wheels and one for the rear wheel, one had decided to form braking function zone (Fig.1a and Fig.1b) at the front of the vehicle, to operate this controls with legs. This concept was used from 2015 in DTT-II and DTT-III model vehicles of Club Avtomobilist University of Ruse and for 2020 foot-operated front brakes will be required for all competitors in Shell Eco-marathon. In our case front bake is set to right leg for better sensitivity and precision (in usual situation), and rear brake - to left leg as spare. 


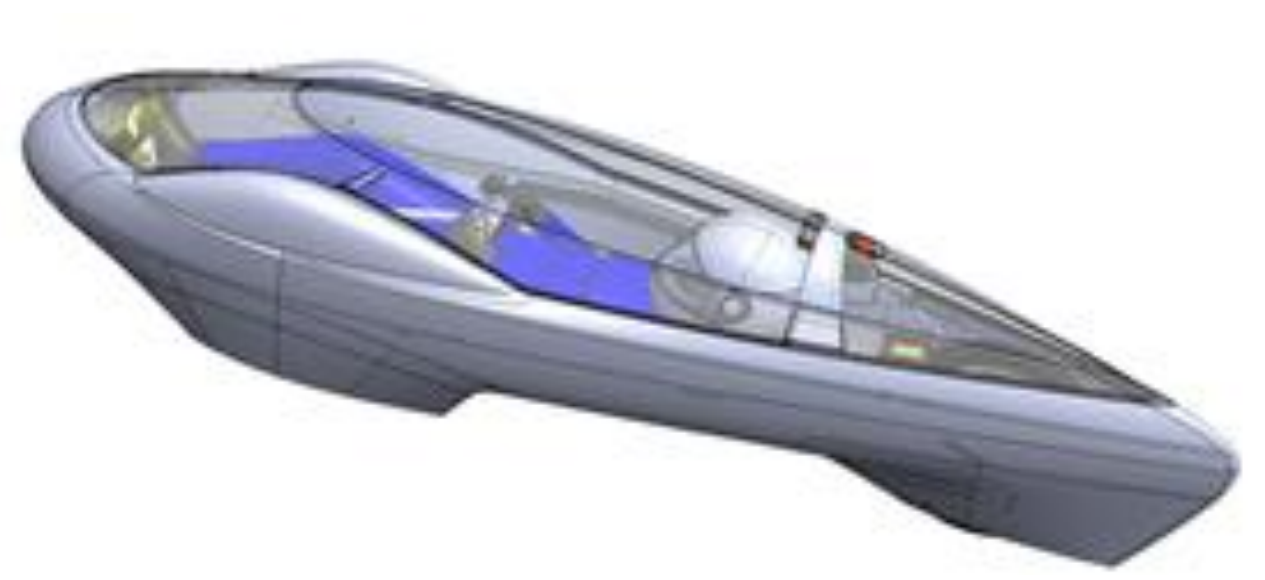

Fig. 1a. Braking function zone in the vehicle (in yellow)

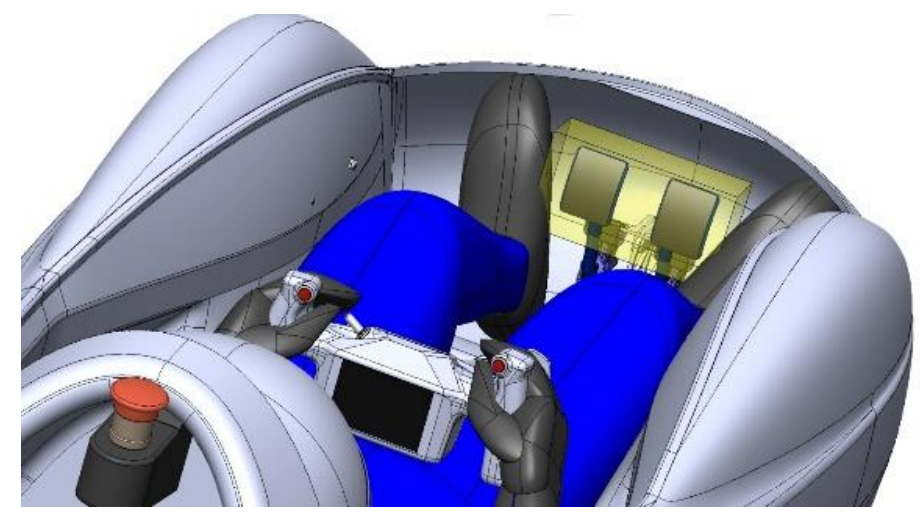

Fig. 1b. Braking function zone

Emergency shutdown actuator - the latching red push button is set close to right hand position in emergency function zone (Fig. 2). In accordance to 2nd principle this zone lies on the path of a right hand in situation of emergency. There are no displays/indicators in this area.

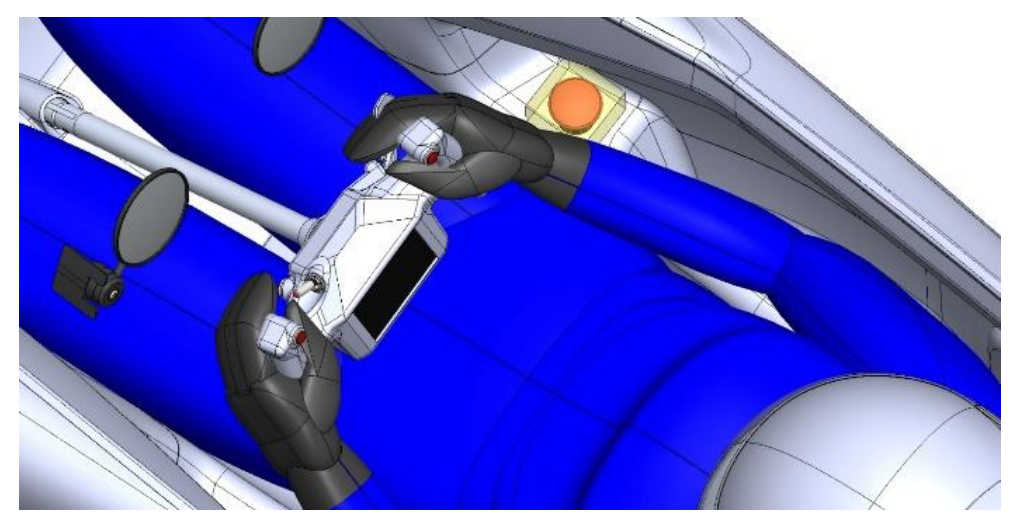

Fig. 2. Emergency function zone

\subsection{Controls and displays/indicators inside steering device's area}

Steering device - using all before mentioned principles and fact that maximum turning angel of the front wheels is $10.81 \mathrm{deg}$., therefore there is no need of a full round wheel. Analyzing different possibilities: joysticks, levers, handlebars, airplane and sports cars steering "wheels", decision was taken to use something close to latter one, because it is like a platform one can build upon on additional number of function zones, but defining this way steering function zone (Fig. 3). Benefits from ergonomic point of view are: hands are kept in their neutral position and can rest by elbows on inside vehicle's panel (Fig. 2), their steering motion is minimal - 16 deg. in each - left and right direction, or not more than 30 $\mathrm{mm}$ vertically, in steering motion hands do not interfere with field of sight. 


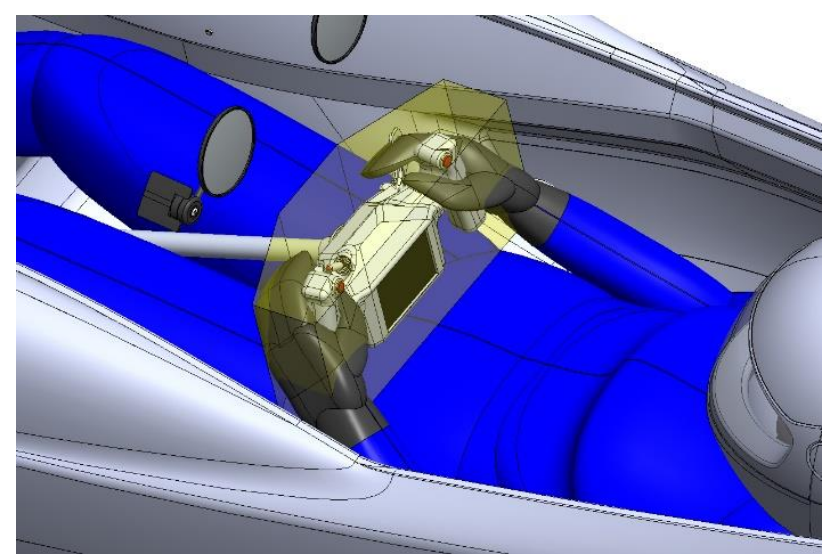

Fig 3. Steering function zone

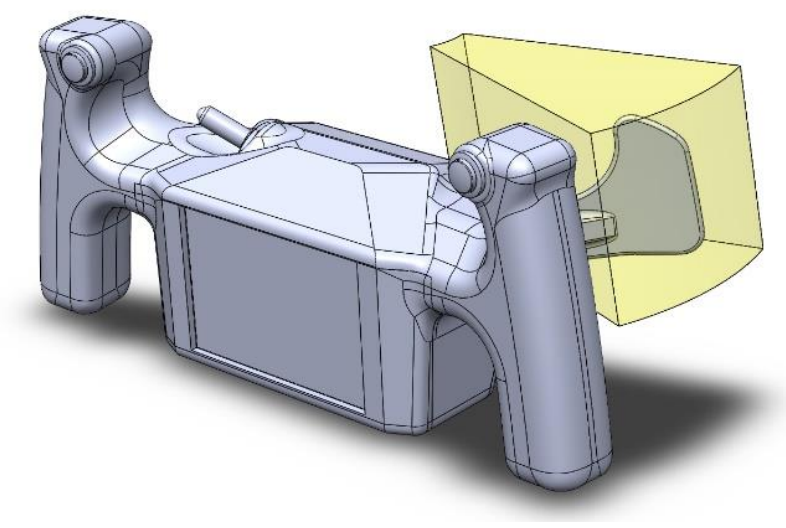

Fig. 4. Motion function zone

Accelerator / "dead man's safety device" - this control by itself is one-turn or slide potentiometer with integrated spring which turns back the shaft or slider to its initial position when three is no physical input on. It is set to be on the right hand steering device's side (team's pilots are right-handed) and form this way - motion function zone (Fig.4). To use especially 2nd and 3rd principle here was extremely difficult, because of the constructive nature of the potentiometers. Their turning angle is $270 \mathrm{deg}$. or minimal travel of $45 \mathrm{~mm}$ (in our case) from both end positions. In DTT- II model this control was based on a slide potentiometer with thumb sized knob (Fig.5). This solution caused thumb muscle fatigue, knowing that the maximal force needed was $1.5 \mathrm{~N}$ and pilots tended to use their proximal phalange or even metacarpal zone of a thumb instead of distal phalange. Using thumb finger to operate this control leaded to another big problem one can do nothing more with the right hand except steering (4-th principle). That's why there was a decision to use a simple proportional mechanism which multiplies travel of input part (lever or slider) to operational part (potentiometer slider) by 2 . This solution gave opportunity to use pedal actuator (operated with index finger, middle finger or both of them), instead of sliding one and to solve before mentioned problems (Fig.6).

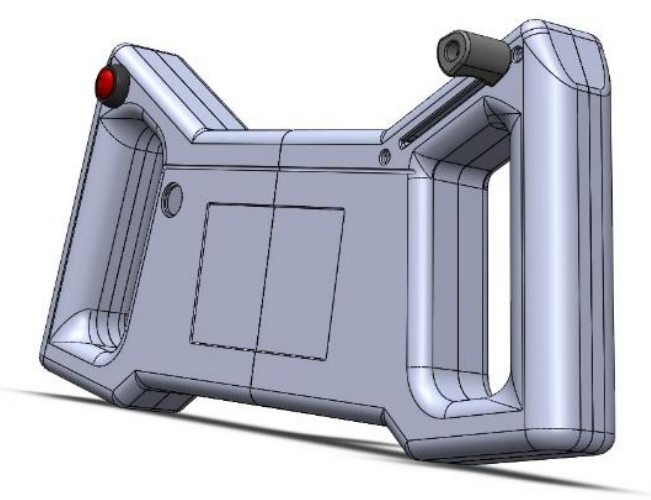

Fig. 5. DTT-II steering device 


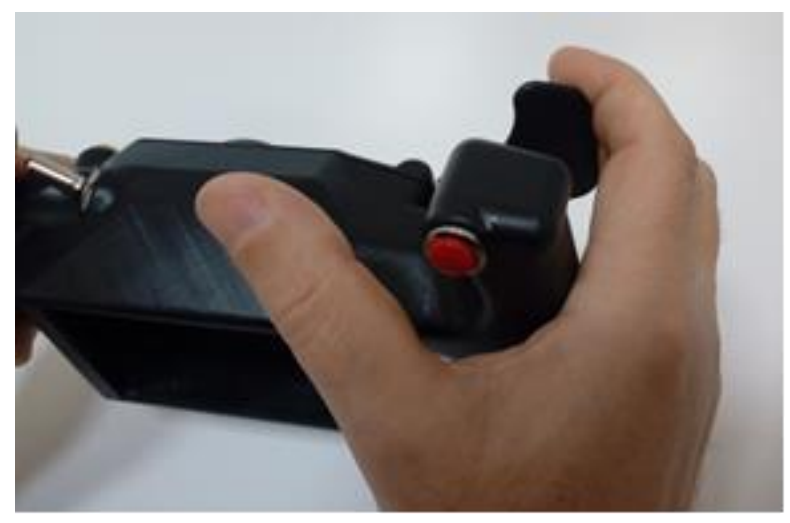

Fig. 6. Operation of pedal actuator control

Start/stop - this control activates and stops the power system of the vehicle and was chosen to be toggle switch with LED-indicator. It is used several times in a lap, switching between active (powered) motion mode and passive (coasting) motion mode. Number of laps in one attempt is 10 to 16 and that's why is important to arrange toggle switch in a position providing easy operation and minimal fatigue - 2 nd and 3 rd principle. This control can be operated with both hands, but to equalize load and to be shortened reaction time, operation was put to the left hand and the toggle switch was set on left of the top main volume's surface of the steering device and form this way power function zone (Fig.7).

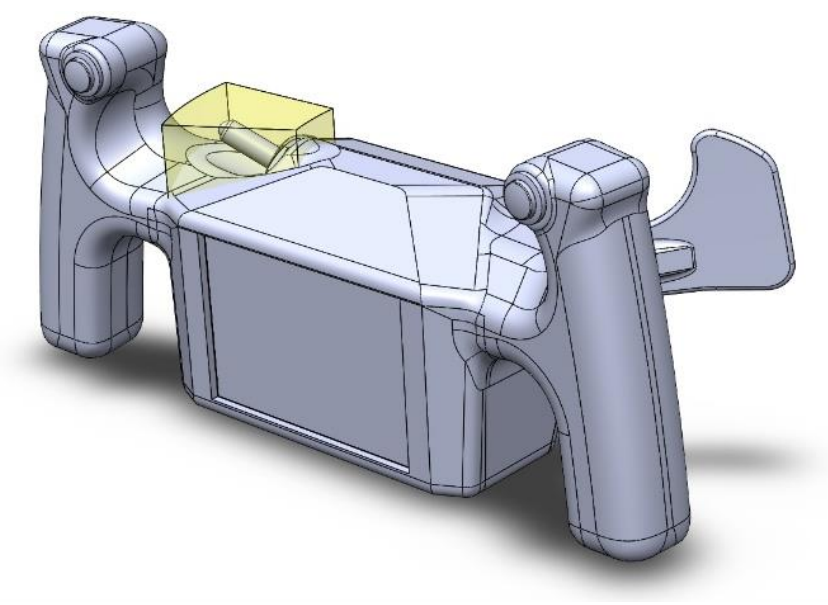

Fig. 7. Power function zone

When the end point of toggle switch knob is in reach of thumb and index fingers and trajectory of its moving coincides with trajectories of thumb grip point and index finger push point trajectories in fingers flexion it can be said this requirements are fulfilled (Fig. 8a and Fig. 8b). Using fingers flexion movement for operating controls is important to minimize pilot's hand fatigue [10].

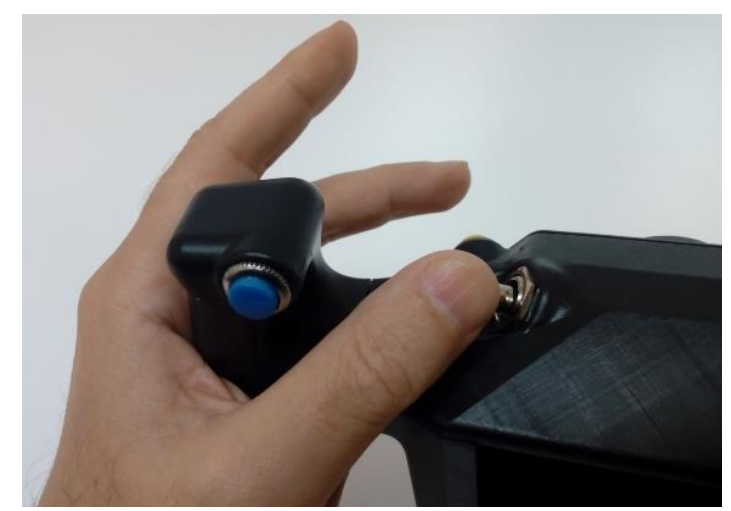

Fig. 8a. Operation of power control - start. 


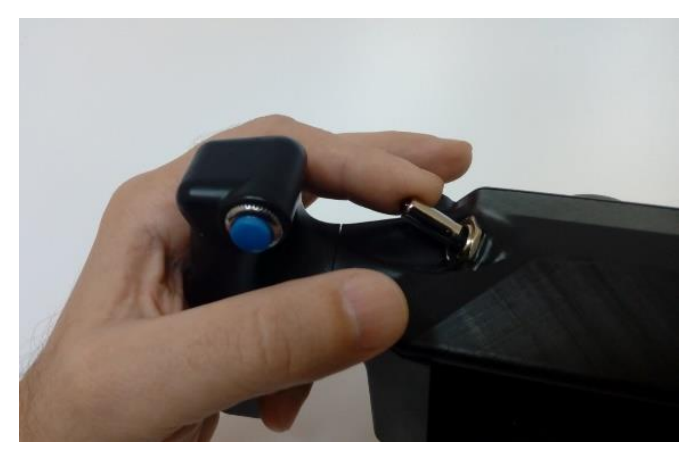

Fig. 8b. Operation of power control - stop

Horn and Calibration - these controls are situated on upper part of handles of the steering device. They related to features and conditions of whole environment (5th principle) and formed this way environment functions zone (Fig. 9).

Horn control is on the left-hand side and is operated with the thumb of the left hand, which interferes with start function of the start-stop control but not with the stop function, more important from efficiency and safety point of view.

Calibration control have to be used at a certain point in time when the pilot is looking outside the vehicle. Control have to be found and activated blindly. These are the reasons to be operated with right hand thumb, which is used for no other operation and don't interfere activities of the other right hand's fingers - 4th principle.

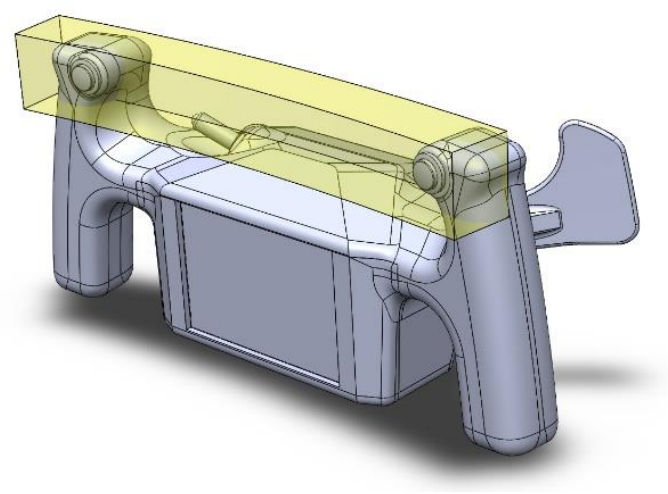

Fig. 9. Environment functions zone

Additional / spare - this control is a button placed on the back, left-hand side of the steering device to be used if there is need for more controls. It presented the variable function zone (Fig. 10).

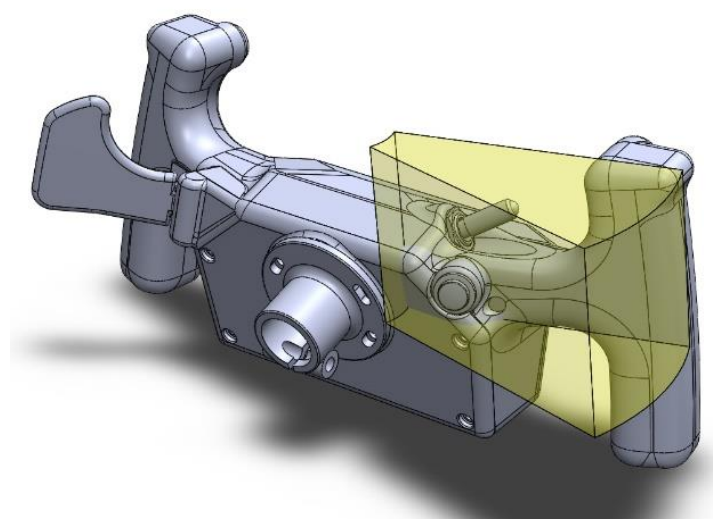

Fig. 10. Variable function zone

Displays and indicators - the only one multifunctional display is situated in the middle of the steering device front side and forms there - display function zone (Fig.11). This zone lies below 15deg normal sight line [10] in the 15deg "preferred display zone" which is optimal for reading displays (2nd principle) and the display is perpendicular to the ground for better visibility and for preventing reflections (Fig.12). 


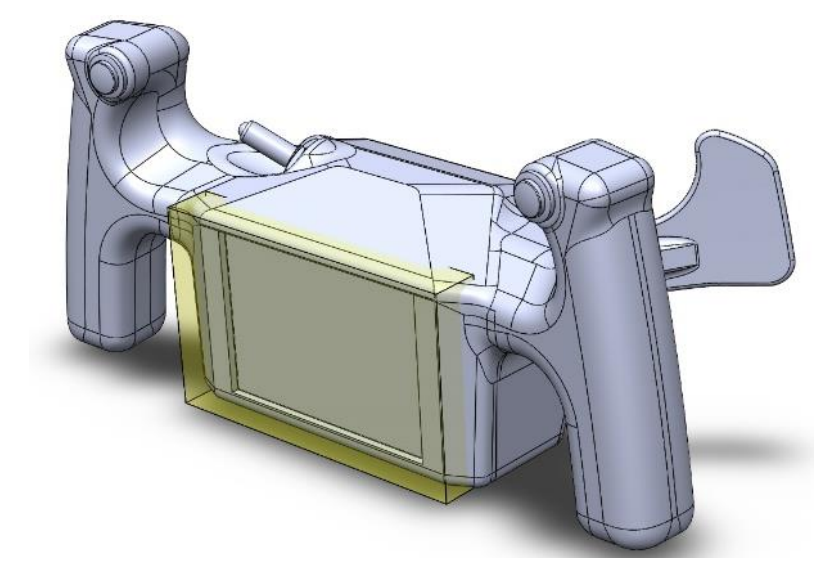

Fig. 11. Display function zone.

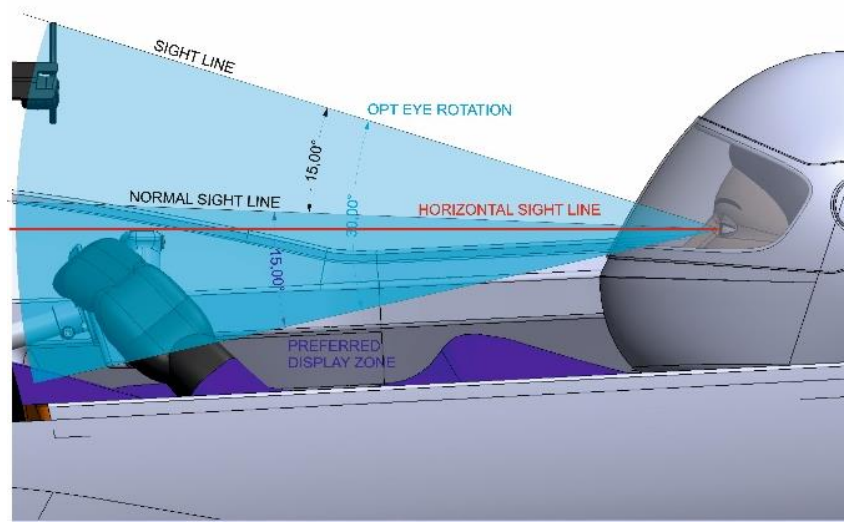

Fig. 12. Sight line and preferred display zone

According to scientific studies [11] and [12], control and display locations must be determined very carefully for both accuracy and safety reasons. In this extreme but not complex case, controls and displays were arranged by named zones, in a way of avoiding action overlap in a process of controls use by timing of action analysis. Zones were also determined by importance, accuracy and needed force. This way there is zone map, which can become mind map of driving process functions. If pattern of interactions between human been and vehicle is added, mental model of driving can be build and refined, making human-vehicle system more secure and efficient.

\section{Management of smart steering wheel}

The controller used to process data received from the signal transducers in the prototype is Arduino DUE (Fig. 13). It is a single-chip computer system that combines a microprocessor, clock generator, operating memory and programmable I/O devices. Often the same chip has different types of computer memory. Unlike microprocessors used on personal computers and other computers, microcontrollers are indispensable in embedded systems and are especially useful when a computer device that performs a large number of or relatively complex functions needs to be implemented.

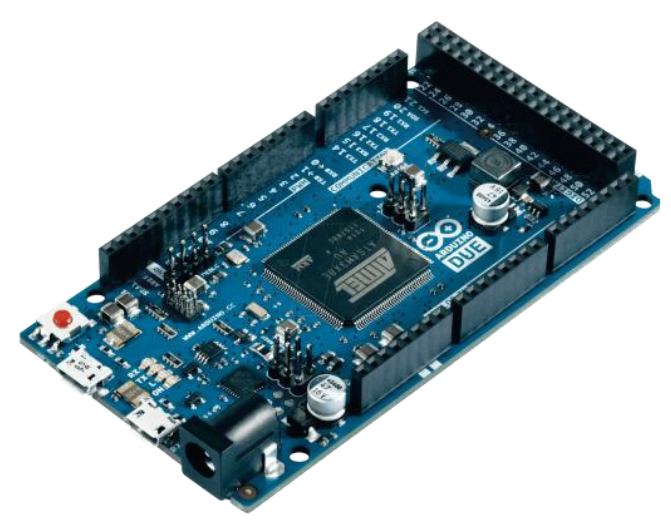

Fig. 13. Arduino Due 32bit ARM Microcontroller 
The Arduino DUE controller is preferred because of its relatively small overall dimensions and low power consumption. On the other hand, its advantages over other controllers are high performance and robust performance under different conditions. This is due to its 32-bit ARM processor, based on the Atmel SAM3X8E ARM Cortex-M3 CPU, which manages 54 digital input and output pins and 12 analogue input pins [13].

In order to implement the programming of the controller, a special programming environment is needed. The company "Arduino" also offers a free interface for this purpose. Arduino IDE is a special programming environment that allows you to write programs for Arduino in a simple language based on Processing [14]. The code is translated to C++, which is usually quite difficult for beginners and is passed on to the avr-gcc compiler - open source software that translates to a comprehensible microcontroller machine language [15]. Most Arduino motherboards have an external power plug that accepts from 6 to 20 volts ( 7 to 19 volts recommended, standard power adapters are mostly 7.5, 9 and 12V), minimum $250 \mathrm{~mA}$ (if there is no additional power consumption by sensors, displays and expansion boards) [16]. Higher supply voltage gives a greater voltage drop in the voltage stabilizer chip and may overheat. There is also an option to use a $9 \mathrm{~V}$ or $12 \mathrm{~V}$ battery. For the prototype, the supply voltage used is $9 \mathrm{~V}$ [17].

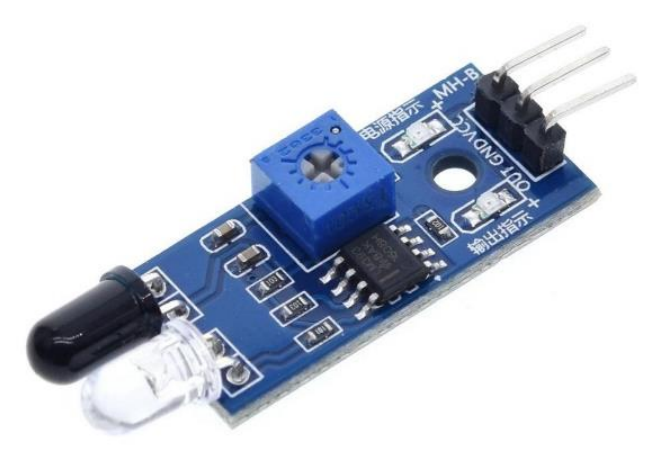

Fig. 14. IR Proximity Sensor

An infrared sensor with parallel infrared LED and infrared phototransistor was used to measure the prototype speed Fig. 14.

An analogue temperature sensor TMP36 was used to measure the temperature of the electric motor is shown on Fig. 15. It allows measuring temperatures in the range of $-40^{\circ} \mathrm{C}$ to $+125^{\circ} \mathrm{C}$, with the input voltage being in the range of $2.7 \mathrm{~V}$ to $5.5 \mathrm{~V}$. Temperature reading is done by varying the voltage, with $10 \mathrm{mV}$ corresponding to $1^{\circ} \mathrm{C}$, and the accuracy of this sensor is $\pm 2{ }^{\circ} \mathrm{C}$.

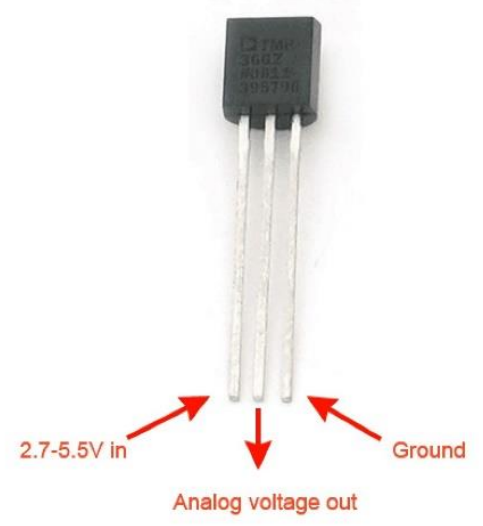

Fig. 15. Temperature sensor TMP36

The steering wheel display (Fig. 16) gives the pilot information about: the laps made (1), the total remaining time (2), the instantaneous speed (3), the current lap time (4) time score (6), momentary lap time (7), electric motor temperature (8), optimal time-of-travel indicator (9), distance travelled within a lap (10) and frames per second (11) - only visible in setup mode. All screen data is located in pilot-friendly positions. Data is saved on an SD card, creating two separate text files: one with average averaged results for each lap and another with detailed results for every second. When the controller is started with the power switch (12), the team logo appears and then the SD card is checked. If it is available then it should be initialized. At startup with a red button pressed, the card deletes both files and then creates two new blank files ready to record the information. 


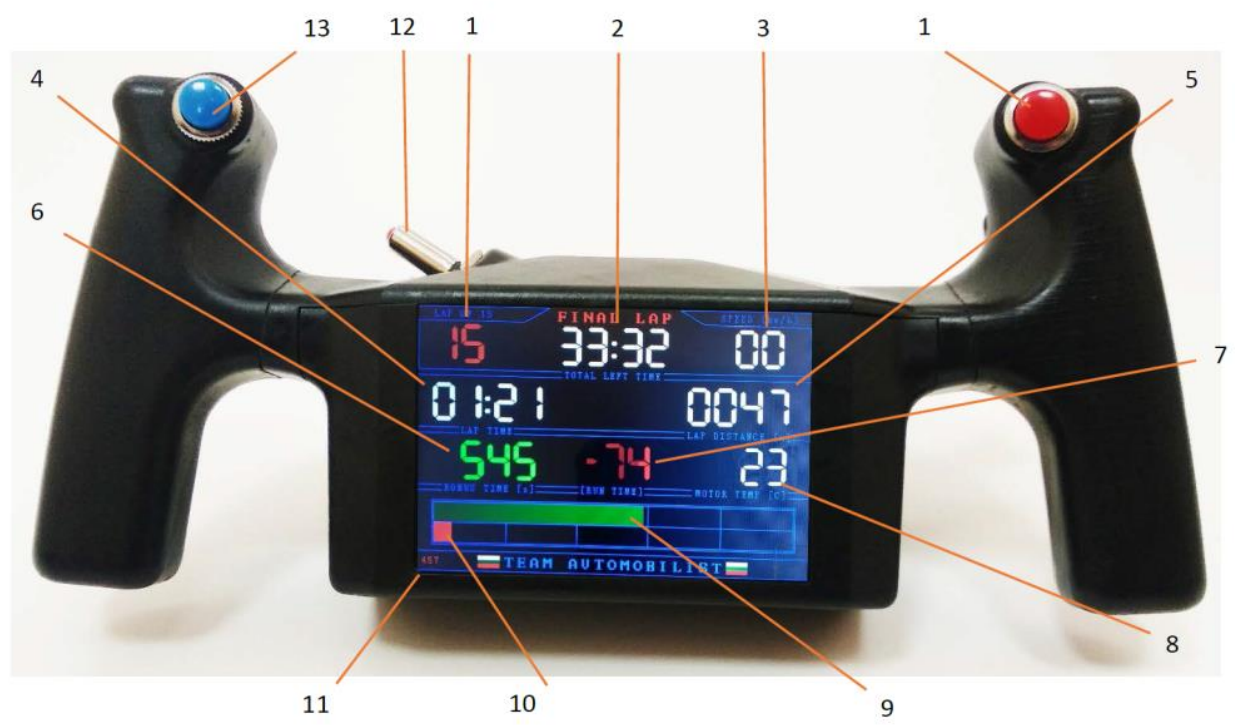

Fig. 16. Steering wheel with display

The indicators represent the location of which must be (green) and the location of the track prototype (red). This helps an easier visualization of the pilot, whether he needs to increase his speed or use the maximum inertia of the prototype. The distance travelled in digital format is shown in position 5 , in meters.

The lap count shows which lap the pilot should leave the track. When the last lap is reached, the counter is colored red and over the total remaining time appears red "FINAL LAP" in order to attract the attention of the pilot. The blue button on the left side (13) is the horn.

\section{Conclusion}

Improving the efficiency of transport vehicles and systems using principles of interaction and programmable units with software based on this principles to its limits, is good intermediate solution and reference point to fully autonomous transportation future.

The advantages of multifunctional steering wheel compared to existing ones are:

- Optimize the engine efficiency and the maximized usage of energy. Many of the powertrain parameters can be tracked and thus optimized for energy consumption. This is achieved by using multifunctional display which is situated in the middle of the steering device front side and forms there - display function zone.

- Good ergonomics on the steering wheel makes it easier for the pilot to work. This work shows the capabilities of a steering wheel used in the energy efficient vehicle. Benefits from the ergonomic point of view are: hands are kept in their neutral position and can rest by elbows on inside vehicle's panel, their steering motion is minimal - $16 \mathrm{deg}$. in each - left and right direction, or not more than $30 \mathrm{~mm}$ vertically, in steering motion hands do not interfere with the field of sight. Using fingers flexion movement for operating controls is important to minimize pilot's hand fatigue.

- Thanks to the steering system with a controller inside, the electric prototype can be optimally controlled and the desired parameters are displayed on the screen, which significantly alleviate the pilot's performance.

- The multifunctional steering wheel was patented.

Thanks to the multifunctional steering wheel were optimized energy efficiency of the electric vehicle prototype, improved ergonomics, minimize pilot's hand fatigue and controlling many of the parameters when driving.

The future research plans are embedded telemetry to allow multiple parameters to be monitored remotely.

\section{Acknowledgments}

The study was supported by contract of University of Ruse “Angel Kanchev”, № BG05M2OP001-2.009-0011-C01. Support for the development of human resources for research and innovation at the University of Ruse "Angel Kanchev". The project is funded with support from the Operational Program" Science and Education for Smart Growth 2014 - 2020" financed by the European Social Fund of the European Union.

The present document was supported with the financial assistance of the Project 2019-RU-03. 


\section{References}

[1] Iliev, S. (2018) A Comparison of Ethanol, Methanol and Butanol Blending with Gasoline and Relationship with Engine Performances and Emissions. In Proceedings of 29th DAAAM International Symposium, Zadar, Croatia, 24h-27th October 2018 (Vienna, Austria), 0505-0514.

[2] Iliev, S. (2017) Investigation of N-Butanol Blending with Gasoline using a 1-D Engine Model. In Proceedings of Special Session on Sustainable mobility solutions: vehicle and traffic simulation, on-road trials and EV charging, Porto, Portugal, 22-24 April 2017 (Porto, Portugal), 385-391.

[3] Iliev, S. (2014) Developing of a 1-D combustion model and study of engine performance and exhaust emissions usingethanol-gasoline blend. Gi-Chul Yang, Sio-Iong Ao, Len Gelman [ed.], IAENG Transaction of Engineering Technologies (Netherlands: Springer), ch. 6.

[4] The Shell Eco-marathon Global Rules 2019, Chapter I (https://www.shell.com/energy-and-innovation/shellecomarathon/europe)

[5] Santin, J. and Honder, C. (2007) The world's most famous fuel efficiency vehicle-Design and Development of PacCar II, 2nd ed. (Switzerland: vdf Hochschulverlag AG).

[6] https://www.shell.com/energy-and-innovation/shell-ecomarathon/about.html

[7] Bridger R.S. (2003) Introduction to Ergonomics. (England: Taylor \& Francis).

[8] Moore, S. M., Torma-Krajewski, J., Steiner, L. J. (2010) Report of Investigations 9684: Practical Demonstrations of Ergonomic Principles. In Proceedings of National Institute for Occupational Safety and Health, Pittsburgh.

[9] Basmajian JV, De Luca C J. (1985) (Year) Muscles alive: their functions revealed by electromyography, 5th ed. (Baltimore: Williams and Wilkins).

[10] Tilley A. (1993) Measure of Man and Woman: Human Factors in Design, 2nd ed. (New York: Whitney Library of Design).

[11] Murata, A. and Moriwaka, M. (2005) Ergonomics of steering wheel mounted switch-how number and arrangement of steering wheel mounted switches interactively affects performance. International Journal of Industrial Ergonomics volume 35: 1011-1020.

[12] Green, P., Kerst, J., Ottens, D., Goldstein, S. and Adams, S. (1987) Driver Preferences for Secondary Controls. The University of Michigan Transportation Research Institute itle UMTRI-87-47

[13] Margolis, M. (2011) Arduino Cookbook. (O'Reilly Media, Inc.)

[14] Fitzgerald S. and Shiloh M. (2012) The Arduino projects book. (Arduino LLC.)

[15] Alasdair A. (2011) IOS Sensor Apps with Arduino. (O'Reilly Media, Inc.)

[16] Banzi M. (2011) Getting Started with Arduino. (O'Reilly Media, Inc.)

[17] Igoe T. (2011) Making Things Talk, 2nd Edition (O'Reilly Media, Inc.) 